\title{
CALIBRATION PROCEDURES FOR TORQUE MEASURING DEVICES BY USING A REFERENCE TYPE TORQUE CALIBRATION MACHINE AT NMIJ
}

\author{
M. Kiuchi ${ }^{1}$, A. Nishino ${ }^{1}$, K. Ogushi ${ }^{1}$ \\ ${ }^{1}$ National Metrology Institute of Japan (NMIJ), AIST, Tsukuba, Japan, kiuchi-misaki@aist.go.jp
}

\begin{abstract}
:
NMIJ / AIST has been disseminating the national torque standard to Japanese industry by using deadweight type torque standard machines (DWTSMs). In general, DWTSMs can generate more precise torque than other types of TSMs. On the other hand, the calibration takes much longer time than others. One possible solution is to use a reference type torque calibration machine (RTCM). RTCMs have been developed in some national metrology institutes (NMIs). We have started the development of the first RTCM in the range of $100 \mathrm{mN} \cdot \mathrm{m}$ to $10 \mathrm{~N} \cdot \mathrm{m}$. In this study, we developed the automatic calibration system of the RTCM and investigated the calibration procedures for a low nominal capacity torque measuring device (TMD). It was found that the calibration could be realised by the RTCM, compared with the reliable DWTSM of rated capacity of $10 \mathrm{~N} \cdot \mathrm{m}$ at NMIJ.
\end{abstract}

Keywords: torque; torque standard; reference torque calibration machine; calibration

\section{INTRODUCTION}

The National Metrology Institute of Japan (NMIJ), part of the National Institute of Advanced Industrial Science and Technology (AIST), has developed three deadweight type torque standard machines (DWTSMs) [1-3], and has used them for the calibration of torque measuring devices (TMDs) for accredited laboratories of the first grade [4] with the relative expanded uncertainty order of $10^{-5}$. Figure 1 shows the SI traceability system proposed by NMIJ. DWTSMs can generate more precise torque than other types of torque standard machines (TSMs). The calibration using DWTSMs, however, takes more extended time than other types of TSMs. Besides, the calibration procedure is restricted to the step-by-step calibration, where it needs loading and unloading weights at the end of the moment arm and maintaining the moment arm at the horizontal position.

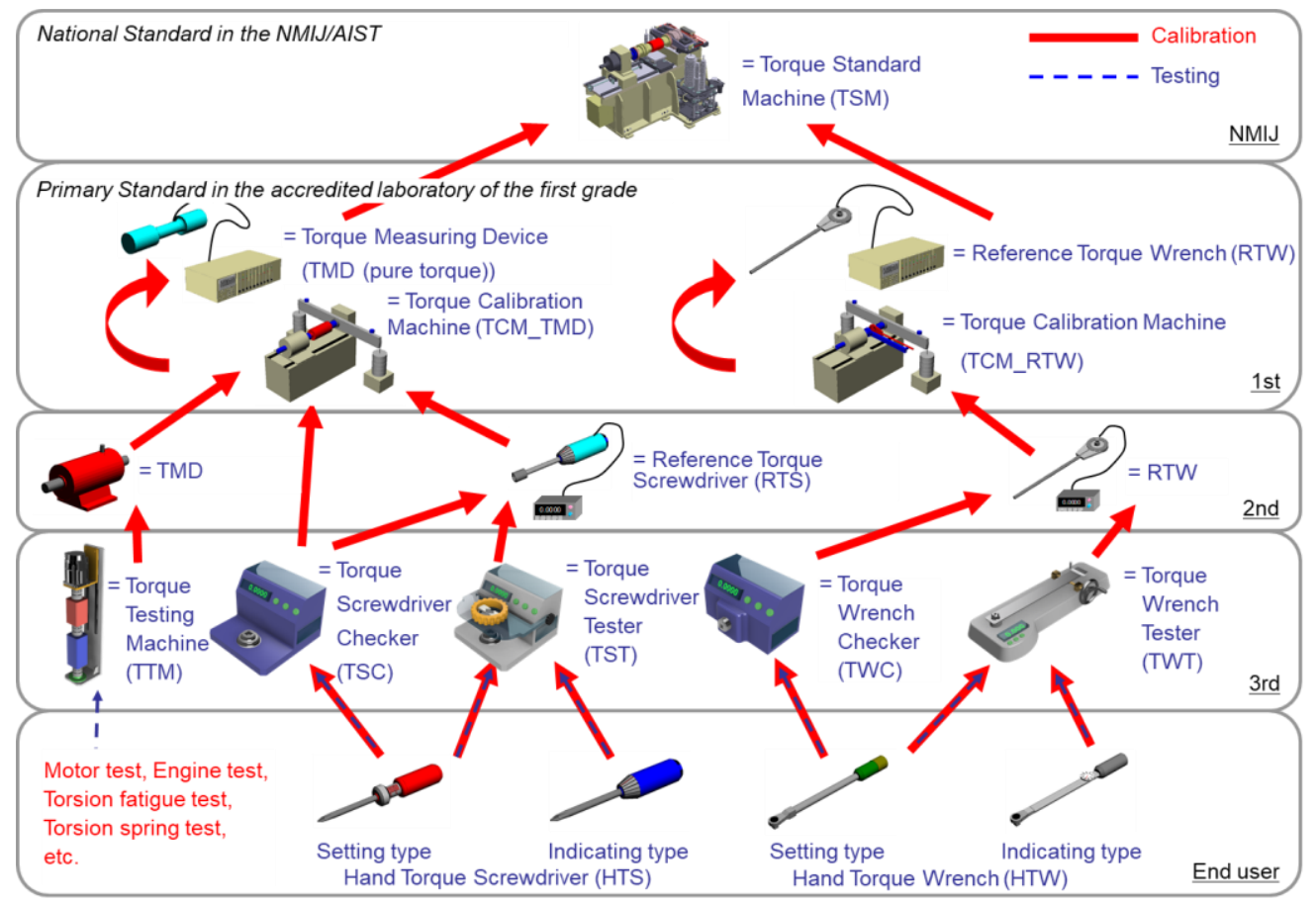

Figure 1: SI traceability system of torque measurement in Japan (proposed) [4] 
Most of TMDs did not need to be calibrated with such a small uncertainty $\left(10^{-5}\right.$ order of relative uncertainty). A kind of efficient or economic calibrations are more preferable for such TMDs in the industry than high-accurate one. So far, some NMIs or accredited laboratories have already been developed and investigated reference type torque calibration machines (RTCM), which are the secondary calibration equipment [5-11]. RTCM generally arrays a reference TMD (R-TMD) with a calibrated TMD (a calibration item: C-TMD) on the same axis. A driving system like as an electrical motor loads the torque on both of R-TMD and C-TMD, then loaded torque could be obtained from the measurement value of R-TMD. R-TMD has been calibrated by using upper level of DWTSM beforehand.

In Japan, an RTCM has been introduced for the calibration service of TMDs but from the range of $10 \mathrm{~N} \cdot \mathrm{m}$ to $10 \mathrm{kN} \cdot \mathrm{m}$ at the Japan Quality Assurance Organization (JQA) [12]. According to our survey of Japanese industry on torque measurement, demands for small range torque calibration is still increasing. Then, we decided to develop a RTCM with lower nominal capacity of less than $10 \mathrm{~N} \cdot \mathrm{m}$ [13]. In addition, the RTCM is possibly able to shorten the calibration time and to investigate new calibration procedures or methods other than the classical style of the step-by-step method.

In this study, first, the authors describe the completed automatic new RTCM. Then, the trial calibration experiment in the range from $100 \mathrm{mN} \cdot \mathrm{m}$ to $1 \mathrm{~N} \cdot \mathrm{m}$ was conducted with various waiting time and motor speed conditions. Finally, we compared the calibration results obtained by the new RTCM to that obtained by the DWTSM with the rated capacity of $10 \mathrm{~N} \cdot \mathrm{m}(10 \mathrm{~N} \cdot \mathrm{m}$ DWTSM). Here, we cannot still name the new RTCM with the capacity although the aimed calibration range will be $10 \mathrm{mN} \cdot \mathrm{m}$ to $10 \mathrm{~N} \cdot \mathrm{m}$ or $100 \mathrm{mN} \cdot \mathrm{m}$ to $10 \mathrm{~N} \cdot \mathrm{m}$.

\section{EXPERIMENT}

\subsection{Experimental Setup}

\section{$10 \mathrm{~N} \cdot \mathbf{m}$ DWTSM}

Figure 2 shows a photograph of the $10 \mathrm{~N} \cdot \mathrm{m}$ DWTSM. The $10 \mathrm{~N} \cdot \mathrm{m}$ DWTSM consists of; (1) a double-side moment arm, (2) a weight loading component, (3) a counter bearing drive, (4) installation components for a torque transducer, (5) a pedestal, and (6) a windshield. The calibration range of it is from $10 \mathrm{mN} \cdot \mathrm{m}$ to $10 \mathrm{~N} \cdot \mathrm{m}$. The calibration and measurement capabilities (CMCs) are $2.0 \times 10^{-4}$ from $10 \mathrm{mN} \cdot \mathrm{m}$ to $100 \mathrm{mN} \cdot \mathrm{m}$, and $7.0 \times 10^{-5}$ from $100 \mathrm{mN} \cdot \mathrm{m}$ to $10 \mathrm{~N} \cdot \mathrm{m}[3,14]$.

The DWTSM was used for the calibration of not only the R-TMD but also the C-TMD in the new RTCM, as described below.

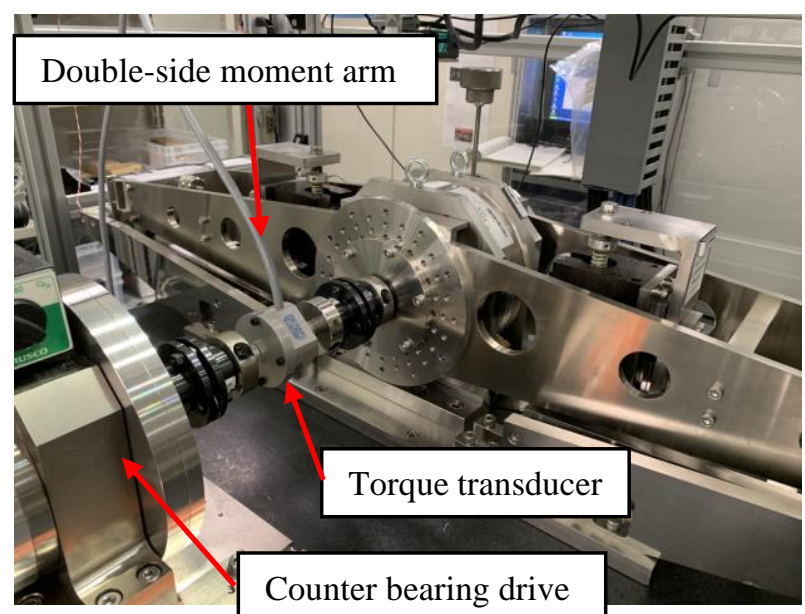

Figure 2: Photograph of the $10 \mathrm{~N} \cdot \mathrm{m}$ dead weight type torque standard machine at NMIJ

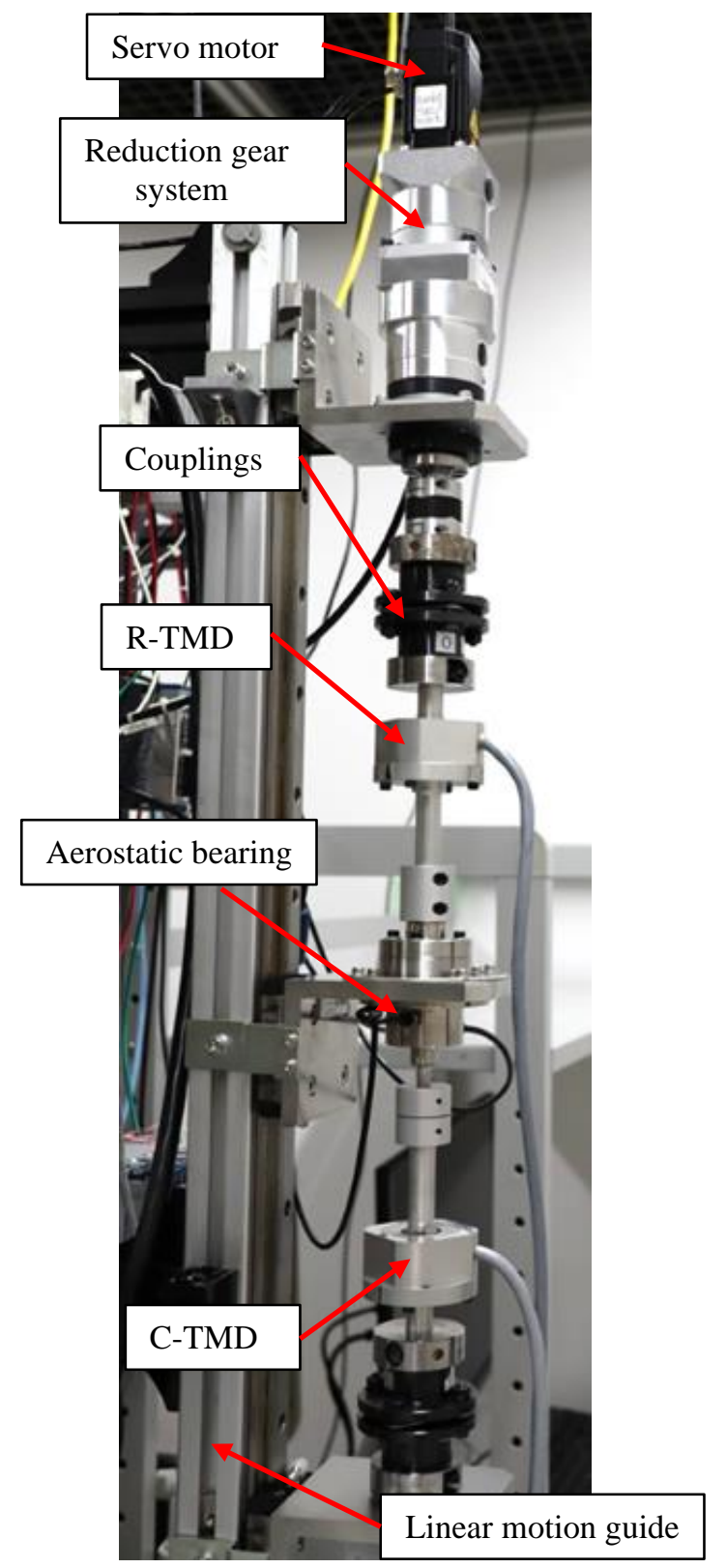

Figure 3: Photograph of the new RTCM 


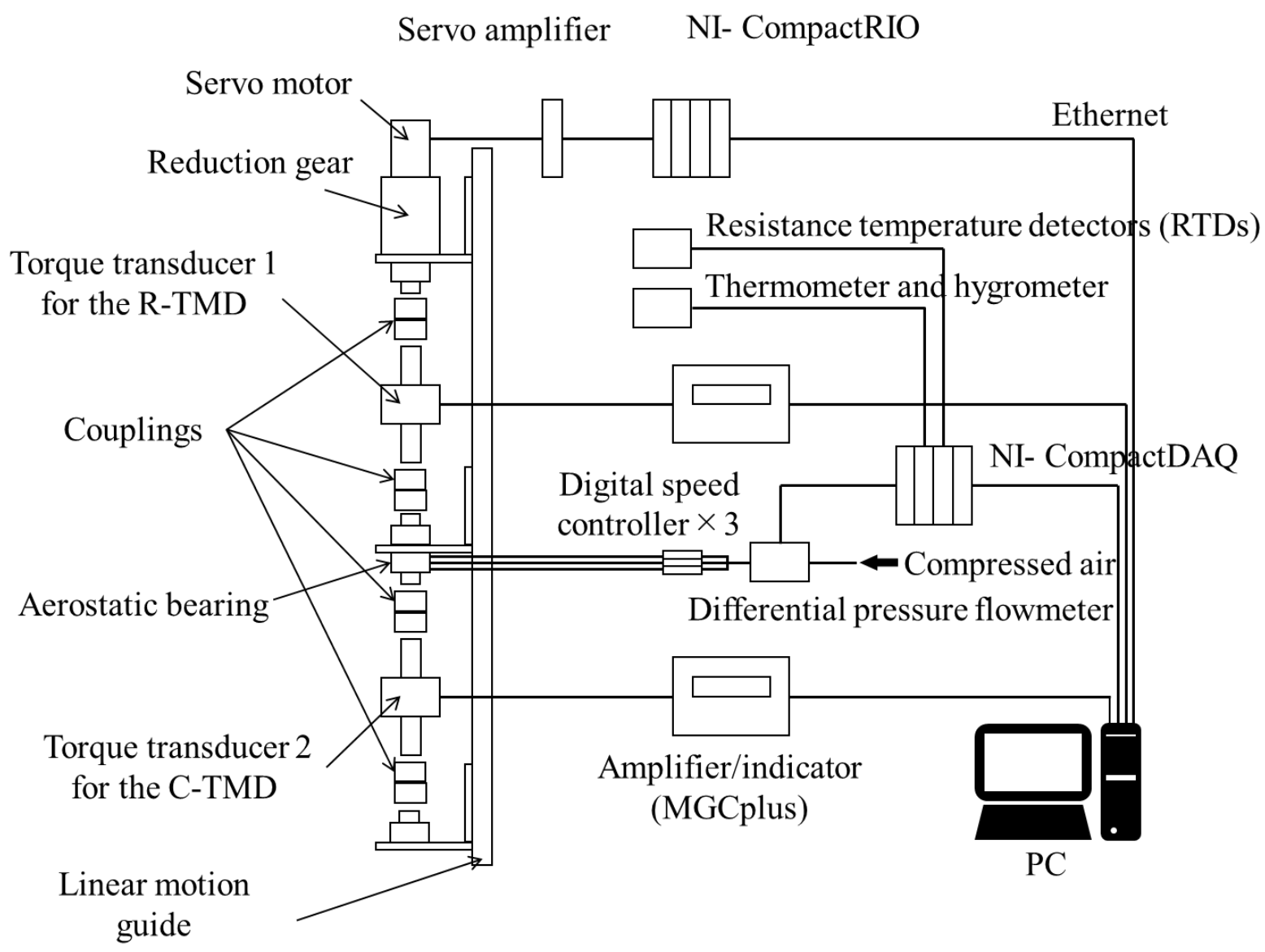

Figure 4: Schematic view of the experimental setup

\section{RTCM}

Figures 3 and 4 show a photograph and a schematic diagram of the new RTCM. The new RTCM is set up vertically (the measurement axis is vertical). The new RTCM consists of (1) a servo motor, (2) reduction gear system, (3) couplings, (4) an R-TMD, (5) an aerostatic bearing, (6) a C-TMD and (7) a linear motion guide. The torque transducer for the R-TMD and another torque transducer for the C-TMD are installed in series. Here, again, TMD is defined as a complete set of a torque transducer, a cable, and an amplifier/indicator [15]. A motor simultaneously twists the two transducers.

In this study, we used TP-1N-0302 as the torque transducer, which was developed by NMIJ in cooperation with Showa Measuring Instruments Co., Ltd., as both transducers for the R-TMD and CTMD. The capacity of the TP-1N-0302 is $1 \mathrm{~N} \cdot \mathrm{m}$. The new RTCM can calibrate the C-TMD by comparing the output of it with the output of the RTMD. Besides, a hygrometer, a barometer, and thermometers are connected to a PC through a highresolution data acquisition system (DAQ). The servo motor is also connected to a PC through a servo amplifier and the motion controller. The velocity values of the servo motor is appropriately able to be controlled by using the PC while monitoring the output of the R-TMD.

\subsection{Experimental procedures}

Calibration procedures for the $10 \mathrm{~N} \cdot \mathrm{m}$ DWTSM

A TSM of a higher-level must calibrate the R-TMD inside the new RTCM beforehand. First, we calibrated the R-TMD by using the $10 \mathrm{~N} \cdot \mathrm{m}$ DWTSM according to a guideline of JMIF-015 [15] The Japan Measuring Instruments Federation published this guideline after discussion among NMIJ, the Japanese industry, and universities.

The C-TMD was also calibrated by the $10 \mathrm{~N} \cdot \mathrm{m}$ DWTSM in order to evaluate the calibration capability of the new RTCM later.

Both TMDs were calibrated separately for the clockwise (CW) and counterclockwise (CCW) directions. At the rotational mounting position of $0^{\circ}$, the torque transducer was preloaded three times in the direction to be calibrated, applying the maximum torque $T_{\max }$, after which, the calibration loading cycles were repeated twice. During one cycle, loading was performed either in eight steps of $10 \%, 20 \%, 30 \%, 40 \%, 50 \%, 60 \%, 80 \%$, and $100 \%$ of $T_{\max }$. Both the two cycles consisted of increasing and decreasing torques. For successive mounting positions of $120^{\circ}$ and $240^{\circ}$, the same calibration cycles as for $0^{\circ}$ were used (after one preloading cycle).

The calibration was conducted as precisely as possible according to a given timetable, in order to 
eliminate the influence of creep in the torque transducers. Each indicated value was acquired after the predetermined waiting time ( $30 \mathrm{~s}$ as the normal condition) from the achievement to each torque step

The above procedure is classically used for the calibration with DWTSMs, so-called "step-by-step" calibration.

\section{Calibration Procedures for the RTCM}

We calibrated the C-TMD by using the new RTCM. For the confirmation that the calibration with the new RTCM just can be conducted with the step-by-step procedure as same as the $10 \mathrm{~N} \cdot \mathrm{m}$ DWTSM, some calibration experiments with different parameters were carried out. However, only the results of one condition for the motor speed are described in Section 3. The motor speed was gradually changed as the torque get closer to the the target value of the next step.

Whereas, the waiting time was set to $30 \mathrm{~s}$ (Condition No. 1) and $60 \mathrm{~s}$ (Condition No. 2). The other calibration procedures and conditions were the same as those described in the previous subsection.

\section{RESULTS AND DISCUSSION}

Figure 5 shows characteristic curves of calibration of the R-TMD obtained by using the $10 \mathrm{~N} \cdot \mathrm{m}$ DWTSM. It can be seen that a transducer with very good characteristics was used as R-TMD.

Figure 6 shows characteristic curves of calibration of the C-TMD obtained by using the $10 \mathrm{~N} \cdot \mathrm{m}$ DWTSM. Characteristic relative deviations were calculated according to Eqs. (33) in reference [4] as deviations from the linear lines from zero to the maximum value of the calibration result. From the figure, the C-TMD could be calibrated in the uncertainty level within $10^{-4}$ order. The characteristic curves are smooth, and the dispersion of each curve is small. The calibration capability of the $10 \mathrm{~N} \cdot \mathrm{m}$ DWTSM has no problem. However, all the calibration (including both $\mathrm{CW}$ and $\mathrm{CCW}$ calibration) took more than eight hours.

Figure 7 also shows characteristic curves of calibration of the C-TMD obtained by using the new RTCM in the condition of No. 1 as the best result. The results obtained with other conditions were not good in a few torque steps because out-of-control might occur in the motion control of the servomotor. Even in Figure 7, it was found that the characteristic curves were not smooth and not successive. That suggests the control of the torque at each step was not stable. Further investigation will be required, especially for the motor-control of the new RTCM. Nevertheless, the scattering of data was within $0.04 \%$ at around the $1 \mathrm{~N} \cdot \mathrm{m}$ step. We could achieve the completion of the new RTCM with the classical step-by-step torque calibration, at least. Moreover, all the calibration could successfully take less than four hours.

The relative deviations of calibration results obtained by using the new RTCM in the condition of No. 1 and No. 2, from the values obtained by using the $10 \mathrm{~N} \cdot \mathrm{m}$ DWTSM were expressed in Figures 8 and 9. the relative deviations were within approximately $0.05 \%$, except at the step of $100 \mathrm{mN} \cdot \mathrm{m}$. They seem to include a kind of systematic error. The remarkable differences of two conditions could not be found. Therefore, the waiting time did not affect the calibration results obtained by the new RTCM so much. The future investigation will solve massive deviations. Large deviations at the steps of $100 \mathrm{mN} \cdot \mathrm{m}$ would probably come from the out-of-control of the servo-motor.

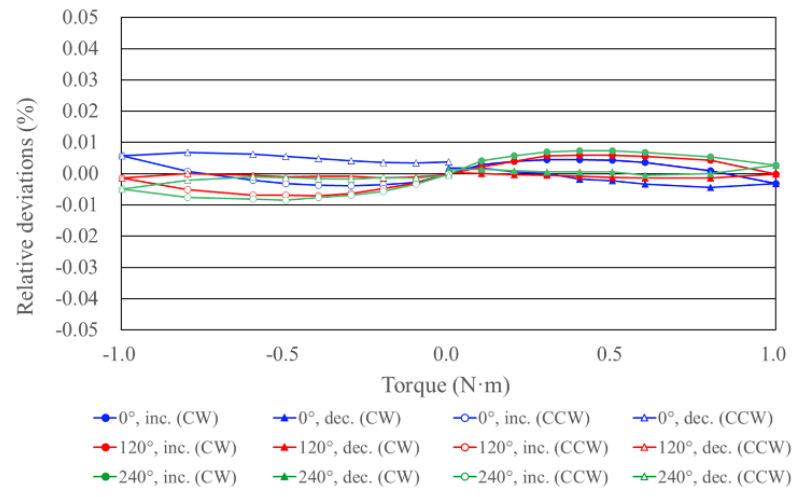

Figure 5: Characteristic curves of calibration of R-TMD by using the $10 \mathrm{~N} \cdot \mathrm{m}$ DWTSM

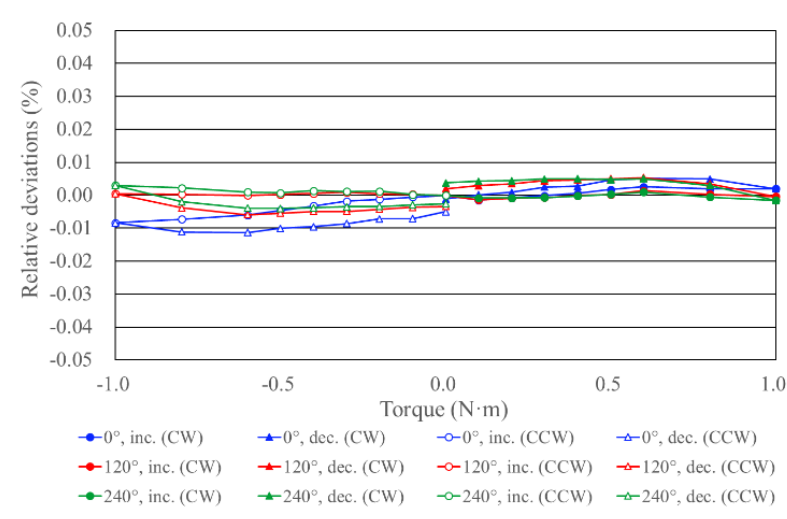

Figure 6: Characteristic curves of calibration of C-TMD by using the $10 \mathrm{~N} \cdot \mathrm{m}$ DWTSM

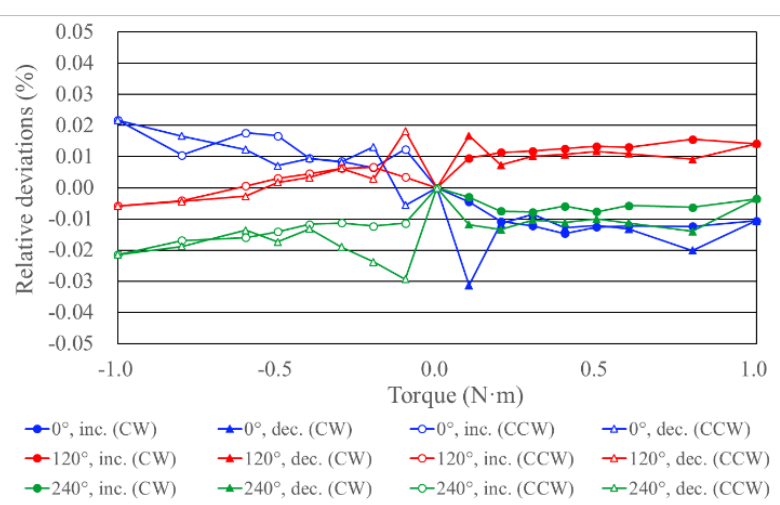

Figure 7: Characteristic curves of calibrationof C-TMD by using the RTCM 


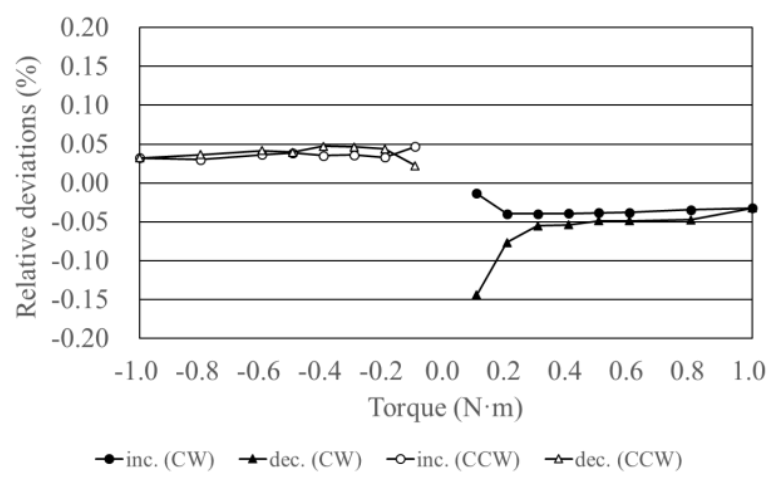

Figure 8: Relative deviation of calibration results using RTCM with condition No. 1, from calibration results using $10 \mathrm{~N} \cdot \mathrm{m}$ DWTSM

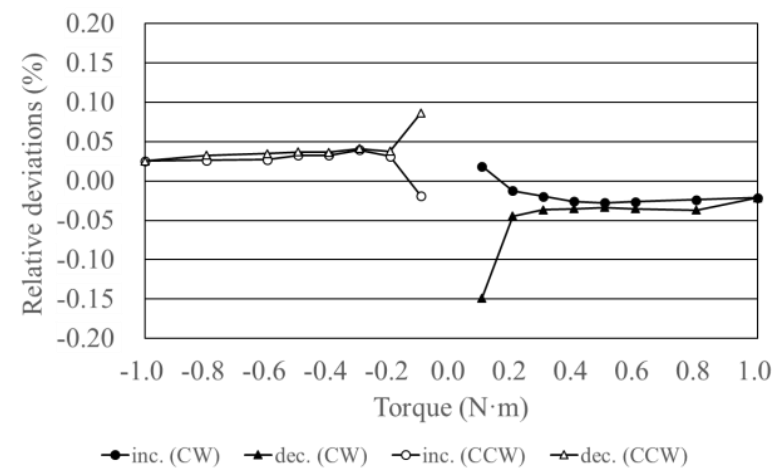

Figure 9: Relative deviation of calibration results using RTCM with condition No. 2, from calibration results using $10 \mathrm{~N} \cdot \mathrm{m}$ DWTSM

\section{CONCLUSION}

The new reference type torque calibration machine (RTCM) was developed at NMIJ. The calibration capability of this machine was investigated at the range of $100 \mathrm{mN} \cdot \mathrm{m}$ to $1 \mathrm{~N} \cdot \mathrm{m}$, compared with the deadweight type torque standard machine with the rated capacity of $10 \mathrm{~N} \cdot \mathrm{m}(10 \mathrm{~N} \cdot \mathrm{m}$ DWTSM). In some experimental conditions, scattering due to changing the mounting position was within $0.04 \%$ at around the $1 \mathrm{~N} \cdot \mathrm{m}$ step. The relative deviations from the value obtained by $10 \mathrm{~N} \cdot \mathrm{m}$ DWTSM were approximately $0.05 \%$ except the step of $100 \mathrm{mNm}$. The authors could achieve the completion of the new RTCM with the classical step-by-step torque calibration, at least.

In the future, the problem of motion-control should be improved. The possible systematic error in the relative deviations between the calibration results by using the new RTCM and the $10 \mathrm{~N} \cdot \mathrm{m}$ DWTSM should be minimized. The estimation of uncertainty for the calibrations would be next research topics.

\section{REFERENCES}

[1] K. Ohgushi, A. Nishino, T. Ota, K. Ueda, "Expansion of the calibration range and improvement of the uncertainty in the $1 \mathrm{kN} \cdot \mathrm{m}$ deadweight torque standard machine", in Proc. of
IMEKO 20th TC3 Int. Conf., Merida, Mexico, 27-30 November 2007.

[2] K. Ohgushi, T. Ota, K. Ueda, "Uncertainty evaluation of the $20 \mathrm{kN} \cdot \mathrm{m}$ deadweight torque standard machine", Measurement, vol. 40, no. 7-8, pp. 797-802, 2007.

[3] A. Nishino, K. Ogushi, K. Ueda, "Uncertainty evaluation of a $10 \mathrm{~N} \cdot \mathrm{m}$ deadweight torque standard machine and comparison with a $1 \mathrm{kN} \cdot \mathrm{m}$ deadweight torque standard machine", Measurement, vol. 49, pp.77-90, 2014.

[4] K. Ogushi, T. Ota, K. Ueda, D. Peschel, D. Röske, H.-J. Tambach, D. Mauersberger, "International comparison of torque standards in the range of 0.5 to $20 \mathrm{kN} \cdot \mathrm{m}$ between PTB and NMIJ", AIST Bulletin of Metrology, Vol. 6, No. 3, pp. 133-139, 2007.

[5] D. Peschel, "The state of the art and future development of metrology in the field of torque measurement in Germany", in Proc. of XIV IMEKO World Congress, Tampere, Finland, 1997.

[6] D. Peschel, A. Brüge, "Calibration of torque measuring devices - step-by-step or continuous procedure", in Proc. of 16th IMEKO TC3 Conf., Taejon, South Korea, 1998.

[7] A. Brüge, D. Röske, D. Mauersberger, K. Adolf, "Influence of cross forces and bending moments on reference torque sensors for torque wrench calibration", in Proc. of XIX IMEKO World Congress, Lisbon, Portugal, 2009.

[8] A. Brüge, "Creep measurements in reference torque calibration machines", in Proc. of 21st IMEKO TC3 Int. Conf., Pattaya, Thailand, 2010.

[9] N. Saenkhum, T. Sanponpute, "A comparison of purely static and continuous torque calibration procedure", in Proc. of IMEKO 22nd TC3 Int. Conf., Cape Town, South Africa, 2014.

[10] N. Saenkhum, T. Sanponpute, "The optimization of continuous torque calibration procedure", Measurement, vol. 107, pp. 172-178, 2017.

[11] H. J. Fraiss, L. Stenner, D. Röske, "Development of a $400 \mathrm{kN} \cdot \mathrm{m}$ torque calibration machine", in Proc. of XXI IMEKO World Congress, Prague, Czech Republic, 2015.

[12] Y. Toda, T. Kurokawa, H. Teshigawara, K. Ogushi, "Calibration of torque measuring devices using the reference type torque calibration machine in JQA", in Proc. of Asia Pacific Measurement Forum on Mechanical Quantities, T-1, 2019.

[13] A. Nishino, M. Kiuchi, K. Ogushi, "Development of a low nominal capacity reference torque calibration Machine", in Proc. of Asia Pacific Measurement Forum on Mechanical Quantities, T-3, 2019.

[14] A. Nishino, K. Ogushi, "Re-evaluation of sensitivity limit in a $10 \mathrm{~N} \cdot \mathrm{m}$ deadweight torque standard machine" (in Japanese), in Proc. of 56th Annual Conference of the Society of Instrument and Control Engineers of Japan, 2017.

[15] JMIF-015, "Guideline for accredited laboratories of Torque Measuring Devices (Pure Torque)" (in Japanese), Japan Measuring Instruments Federation, 2004. 